(showing that this structure depends upon two gametic characters, instead of one as hitherto supposed), and with comb-lop (showing that the direction of the lop is not apparently inherited). Chapters X. and XI. deal with various phases of the inheritance of plumage, color and pattern. A general gametic formula for poultry coloration is worked out and evidence presented in its favor. Data are given regarding the inheritance of certain pattern types.

The last chapter is devoted to a general discussion of certain theoretical matters of prime importance. Stress is laid upon the possible significance of "inhibitors" in addition to "determiners" in ontogeny. The "principle of imperfect dominance" is discussed at length. One fancies that here is where the greatest disagreement will be found amongst students of the subject. The reviewer, frankly, is unable to see that degree of heuristic worth in this concept which the author seems to find. It seems possible to account for all the facts on which this concept rests in other ways, not any the less in accord with Mendelian principles. Virtually these facts amount to an apparent failure of segregation. One may safely say that practically all students of inheritance whose study involves a real, first hand acquaintance with the living, breeding organisms are deeply impressed with the precision and definiteness of segregation generally. When apparent exceptions to the law of precise segregation occur one's zeal is aroused to discover, the cause. There is a wide range of physiological factors beyond such things as "imperfection of dominance" which must be considered here (teste the work of Tower and of Tennent, for example). Probably every one will admit that the data now available do not permit any final conclusion as to what are the primary factors involved in causing apparent exceptions to Mendelian principles, either in general or in particular cases. What clearly are needed are more of such extensive collections of definite experimental data as are furnished in the work under discussion. We may well observe that caution expressed by Robert Boyle as an apol- ogy for not taking a more decided stand on theoretical questions: "having met with many things for which I could assign no probable cause, and with some for which many different ones might be alleged, I dare speak positively and confidently of very few things except of matters of fact."

\section{Raymond Pearl}

The Teaching Botanist. A Manual of Information upon Botanical Instruction. By William F. Ganong, Ph.D., Professor of Botany in Smith College. Second edition. Pp. $12+439$, illustrated. New York, The Macmillan Company. 1910.

At a time when the teaching profession is being assailed on all sides with demands for a practical education, and when the meaning of "practical" is, in the main, materialistic, those teachers in botany still committed to ideals, but perhaps finding difficulty in harmonizing them with the proper demands of those seeking immediately useful training, will find a champion in the author of "The Teaching Botanist." Professor Ganong has worked long and consistently with the avowed purpose of trying to solve the problem of the content and method of an elementary course in botany. He may therefore be looked upon by the teacher seeking guidance as among the safest and surest. He would be the first to disavow the claim that he has quite answered the question to which his book is a large and satisfying reply, but we do not hesitate to say that he is far along on the right track.

"The Teaching Botanist" in its present form is called a second edition, but is very largely a rewriting. On the side of information, which the teaching botanist desires to have respecting the materials with which he deals, it has been brought down to date. The results of actual teaching experience during the last few years have been set down. In this sense the book is practical, in some directions almost encyclopedic, and will stand in good stead to one who is planning courses or equipping a laboratory. This will be understood to include also the matter of books, which are well discussed, and of which a full 
list, so far as pertains to the teaching of elementary botany, is provided. Since school boards are sometimes in a hurry for data, it would have been well to facilitate the teacher's task by indicating in the list itself the relative values of the various books, so that a limited choice might be quickly made. This end is, however, largely attained in the reading of a chapter, but in a less concise way.

A very valuable addition in the present book are the suggestions given for the growing of plants in windows in pots and boxes. But few schools are able to do more than this, and any practical help in this apparently easy, but really rather difficult matter, will prove very welcome, especially as this part of the text comes from the hand of Mr. Edward J. Canning, than whom few are more skilful in horticultural practise. An additional suggestion will not be amiss, that tin cans are usually better than pots for house culture. Indeed, they are exceedingly useful for much laboratory experimentation. The jagged rims may be melted off, while a coat of asphalt paint will make them sightly.

During the past few years Professor Ganong and some of his more advanced students have systematically . investigated the commoner plants with particular reference to their adaptability for demonstration and laboratory experimentation, while Professor Ganong himself has worked arduously in the perfection of apparatus of more refined type adapted to school and college use. The excellent data and apparatus thus obtained are available in The Botanical Gazette and in another book, "Plant Physiology," properly to be regarded as a companion volume to "The Teaching Botanist," and which should, with this, be in the hands of every ambitious teacher.

The second part is devoted to a detailed discussion of a synthetic course, the content of which is widely known through the work of the Committee on Education of the Botanical Society of America, of which Professor Ganong is the chairman. The method of presentation is left, in the report of that committee, ${ }^{1}$

${ }^{1}$ This report is printed as an appendix. as a matter of choice to the teacher, but the book before us will do much to advance the recognition of the principle of synthesis. The account, covering 150 pages, may be regarded as a condensed log of a successful teacher, and gives the practical pedagogy on every difficult and important point. The fundamental principle, that of synthetic treatment of allied structural and physiological topies, has much to commend it, the chief of which is the overwhelming importance of physiology. The reviewer is glad that the efforts of Professor Ganong have been in this direction, since it is principally this phase of botanical science which must come to the front in the botany taught in schools of agriculture. These are rapidly multiplying, and many young teachers are going out year by year into this work who need much help along the right path.

Of most permanent importance, in the opinion of the reviewer, is the chapter on the Training and Traits of the Good Botanical Teacher. It is full of good common sense coupled with a clear vision of the ideal. The teacher who is troubled because he can not do research will find in this homily some other matters to think about and other ways of advancing his science than in striving to do the work of others whose business it is. There must be a great majority of good botanical teachers whose chief interest is the development of the teaching aspect of the science, and whose effort is legitimately expended in this way. To such Ganong brings a message.

Francis Ernest Lloyd

Alabama Polytechnic Institute

Lehrbuch der anorganischen Chemie. Von Professor Dr. H. ERDmann, Direktor des Anorganisch-Chemischen Instituts der Königlichen Technischen Hochschule zu Berlin. Fünfte Auflage. (Dreizehntes bis Sechszehntes Tausend.) Mit dem Porträt des Verfassers in Gravüre, 319 Abbildungen, 95 Tabellen, einer Rechentafel und Sieben Farbigen Tafeln. Braunschweig, Friedrich Vieweg und Sohn. 1910. Pp. 805. 16 Marks. 